\title{
Las Poáceas del Parque Nacional Yanachaga-Chemillén (Oxapampa, Perú). Parte II: Pooideae, Centothecoideae, Arundinoideae, Chloridoideae y Panicoideae
}

\author{
Poaceae from Yanachaga-Chemillén National Park (Oxapampa, Peru). Part II: \\ Pooideae, Centothecoideae, Arundinoideae, Chloridoideae and Panicoideae
}

\author{
María I. La-Torre ${ }^{1,2}$, Asunción Cano² y Oscar Tovar².
}

Presentado: $18 / 11 / 2003$

Aceptado: $\quad 16 / 02 / 2004$

\section{Resumen}

Se presenta la segunda parte de un estudio taxonómico de la Familia Poaceae del Parque Nacional Yanachaga-Chemillén y zonas aledañas (Oxapampa, Pasco, Perú). Se presentan 63 especies de Poáceas de las subfamilias Pooideae, Centothecoideae, Arundinoideae, Chloridoideae y Panicoideae, las cuales están incluidas en 37 géneros y 12 tribus. Se incluye una breve descripción de los géneros. Se ha elaborado claves para diferenciar los géneros y especies. Para cada especie se indica su ecología, distribución y el material estudiado.

Palabras clave: Poaceae, Pooideae, Yanachaga-Chemillén, Perú

\section{Abstract}

This is a second part of biodiversity study of Poaceae family from Yanachaga-Chemillen National Park and surroundings places (Oxapampa, Pasco, Peru). This part is dedicated to diversity of follow subfamilies: Pooideae, Centohecoideae, Arundinoideae, Chloridoideae and Panicoideae. A total of 12 tribes, 37 genera and 63 species have been registered. Descriptions of genera and keys for genera and species are developed. Ecology, distribution and studied material are indicated.

Keywords: Poaceae, Pooideae, Yanachaga-Chemillén, Peru

\section{Introducción}

El Parque Nacional Yanachaga-Chemillén está situado en el departamento de Pasco, provincia de Oxapampa y en los distritos de Pozuzo, Huancabamba, Oxapampa y Villa Rica $\left(10^{\circ} 35^{\prime}\right.$ y $10^{\circ} 10^{\prime} \mathrm{S}$ y $75^{\circ} 10^{\prime}$ y $75^{\circ} 45^{\prime}$ O) (Fig. 1).

En la primera parte de este estudio, presentamos los resultados correspondientes a la Subfamilia Bambusiodeae (sensu lato) que incluyen a los bambúes leñosos y herbáceos, y que representan el $27 \%$ del total de la flora agrostológica del parque Yanachaga-Chemillén (La Torre et al., 2003). El 73\% restante lo constituyen principalmente Poáceas herbáceas

\footnotetext{
${ }^{1}$ Facultad de Ciencias Naturales y Matemáticas, Universidad Nacional Federico Villarreal, Calle San Marcos, 351, Lima 21.

${ }^{2}$ Museo de Historia Natural, Universidad Nacional Mayor de San Marcos, Avda. Arenales 1256, Lima 11.

E-mail, Maria I. La-Torre: marycano_11@yahoo.com
}

de las subfamilias Pooideae, Centothecoideae, Arundinoideae, Chloridoideae y Panicoideae; cuyas tribus, géneros y especies presentamos en esta segunda parte.

Siendo este trabajo parte de un mismo estudio, el área de estudio, los materiales y métodos empleados son los mismos que los presentados en la primera parte (La Torre et al., 2003). Para la determinación de los taxa, además de los trabajos citados en la primera parte, han sido de gran importancia los trabajos de Tovar (1960, 1965, 1972, 1993).

\section{Clave para determinar las tribus de las subfamilias}

1a. Espiguillas unifloras o multifloras, si son bifloras entonces ambas hermafroditas o la superior estéril; raquila articulada generalmente por encima de las glumas, de modo que estas persisten después de la caída de los granos en la madurez, espiguillas lateralmente comprimidas. 
2a. Inflorescencia en espiga dística o unilateral, fasciculada o esparcida a lo largo del raquis en el ápice de la caña florífera.

Chlorideae

2b. Inflorescencia en panoja laxa abierta o contraída hasta espiciforme, pero no dística ni unilateral.

3a. Espiguillas con una sola flor fértil hermafrodita o con una flor fértil y 1-2 estaminales o estériles basales o con flores unisexuales monoicas.

4a. Espiguillas con una sola flor fértil y una estaminal basal.

\section{Arundinelleae}

4b. Espiguilla con una sola flor fértil y dos estaminales o estériles basales comúnmente reducidas a escamas.

Phalarideae

5a. Glumas más cortas que la lema o excepcionalmente la superior igual.

Sporoboleae

5b. Glumas más largas que la lema.

6a. Lema endurecida, rígida o papirácea, con arista apical generalmente retorcida; callo comúnmente pubescente, agudo-pungente.

Stipeae

6b. Lema membranácea, mútica o con arista dorsal; callo no pungente.

Agrostideae

3b. Espiguillas con dos o más flores hermafroditas o con flores unisexuales. 7a. Espiguilla con lema y raquila cubierta de largos pelos sedosos; plantas robustas comúnmente con cañas subleñosas mayores de $1 \mathrm{~m}$ de altura.

Arundineae

7b. Espiguilla con lema y raquila glabra o escasamente pubescente; plantas herbáceas, comúnmente menos de $1 \mathrm{~m}$ de altura.

8a. Lígula membranácea.

9a. Hojas con seudopecíolo, láminas con nervaduras transversales, anchamente lineares o aovadas.

\section{Centotheceae}

9b. Hojas sin seudopecíolo, láminas sin nervaduras transversales conspicuas.

Poeae

$$
\text { 8b. Lígula pestañada. }
$$

Eragrostideae

1b. Espiguillas 1-2 floras, pero solo la flor superior fértil y la inferior masculina o estéril, comúnmente representada por la lema (excepto en Isachne en que las 2 flores son fértiles), o espiguillas unisexuales monoicas; raquila articulada por debajo de las glumas, de modo que las glumas caen junto con los granos en la madurez; espiguilla comúnmente dorsiventralmente comprimidas.

10a. Espiguillas comúnmente solitarias, glumas membranáceas, la inferior generalmente más pequeña o ausente; lema fértil endurecida, rígida. Paniceae

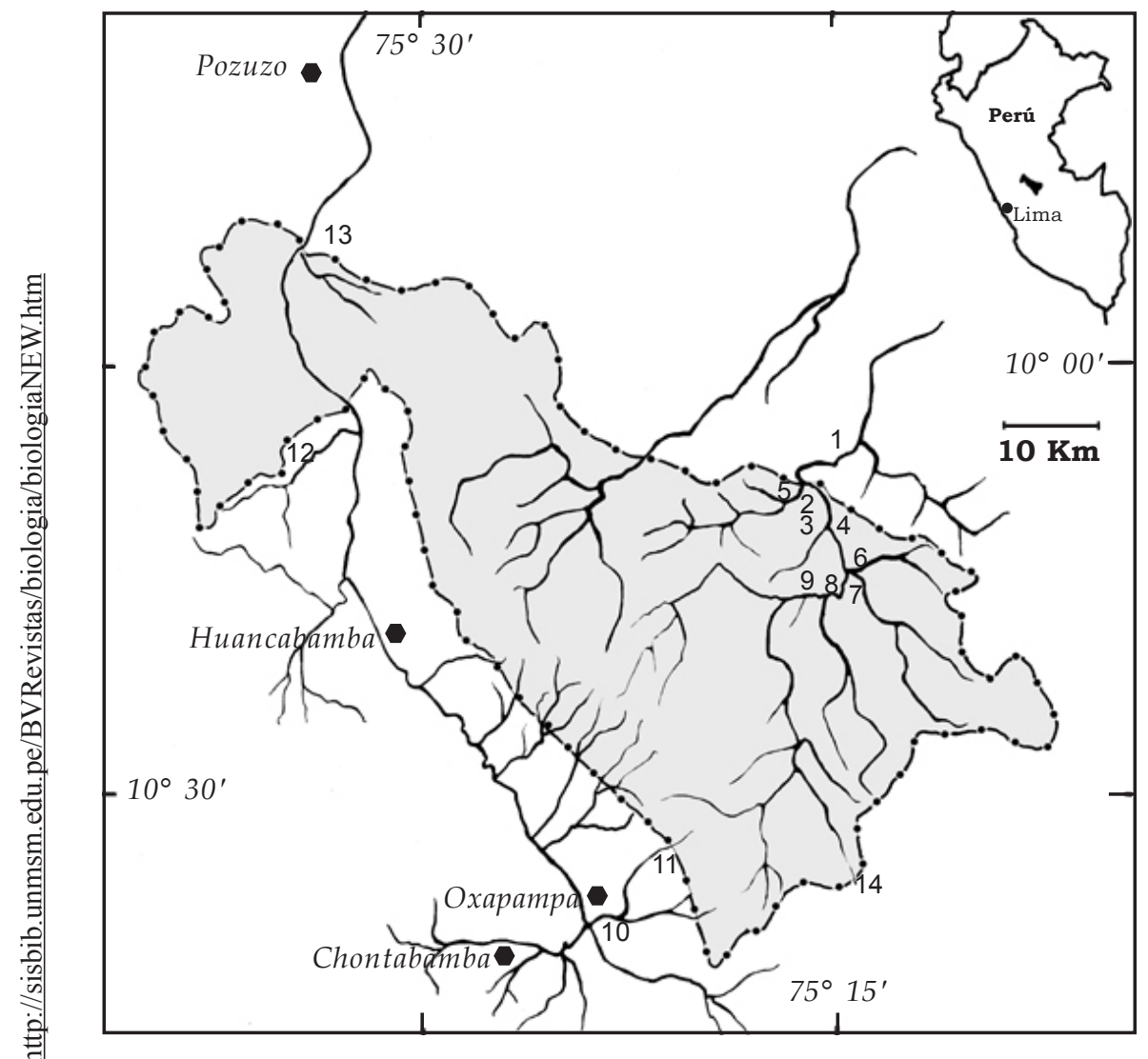

Figura 1. Mapa del área de estudio mostrando la ubicación de las localidades de colecta. (1) Playa Caliente, (2) Estación ecológica de Paujil, (3) Mirador, (4) Río Venado, (5)Río Paujil, (6) Río Lobo, (7) Sub-estación Río Pescado, (8) Río San Carlos, (9) Laguna Luna Llena, (10) Oxapampa, (11) SanAlberto, (12) Santa Bárbara, (13) Quebrada Tunqui, (14) Cerro Pajonal San Gotardo. 
10b. Espiguillas en pares (una sésil hermafrodita y otra pedicelada estéril), o con flores unisexuales, monoicas glumas comúnmente endurecidas; lema fértil membranácea.

Andropogoneae

\section{Subfamilia Pooideae (Festucoideae)}

\section{Tribu Stipeae}

Género Ortachne (Swallen) Clayton

Plantas perennes, densamente, cespitosa, crece en matas o macollos; hojas erectas involutas; inflorescencia en panoja laxa; espiguilla uniflora; glumas cortas, truncadas o emarginadas, anchas; antecio mucho más largo que las glumas; lema con arista apical engrosada; pálea más corta que la lema. A nivel mundial se conoce una sola especie. Se distribuye en Costa Rica, Venezuela, Colombia, Perú y Bolivia.

\section{Ortachne erectifolia (Swallen) Clayton}

Habita en los pajonales de la puna. Especie frecuente en el páramo y la puna desde Costa Rica hasta Perú y Bolivia. En el Perú se ha registrado en los departamentos de Junín y Pasco.

Material estudiado: Provincia de Oxapampa, Santa Bárbara 3300-3420, D. N. Smith 8079 (MO); Santa Bárbara, 3100-3300 m, M. I. La Torre 1552 (USM).

\section{Tribu Poeae (Festuceae)}

\section{Clave para diferenciar los géneros de la tribu Poeae}

1a. Lemas 8-11 nervadas; espiguillas comúnmente mayores de $10 \mathrm{~mm}$ de largo; ovario pubescente en el ápice.

Bromus

1b. Lemas 5-7 nervadas; espiguilla menor de $10 \mathrm{~mm}$ de largo; ovario generalmente glabro.

2a. Lema aguda o aristada, con el dorso convexo.

Festuca

2b. Lema obtusa o aguda con el dorso aquillado, excepto en Poidium.

3a. Espiguilla lanceolada, aovada u oblonga; lema aquillada en el dorso.

Poa

3b. Espiguilla elíptica, ligeramente inflada, lema convexa en el dorso.

Poidium

\section{Género Bromus Linnaeus}

Plantas anuales o perennes, de porte mediano. Lámina plana, lígula membranosa. Panícula abierta o contraída. Espiguillas multifloras, lateralmente comprimidas. Glumas 2, desiguales, menores que la espiguilla; lema de 7-11 nervadas, aquilladas, por lo general aristadas.

El género cuenta con 150 especies en el mundo, seis especies en el Perú y dos especies en la zona de estudio. Se le encuentra en regiones templadas de ambos hemisferios.

\section{Clave para diferenciar las especies del género Bromus}

1a. Lemas escabrosas, aristas de 5-9 $\mathrm{mm}$ de largo.

$$
\text { B. segetum }
$$

1b. Lemas moderadamente pubescentes o densamente villoso-pubescente, aristas menores de $5 \mathrm{~mm}$ de largo.

B. pitensis

\section{Bromus segetum Kunth}

Su hábitat es el bosque montano oriental y se distribuye en Colombia, Ecuador y Perú. En el Perú habita los niveles medios del flanco oriental de los Andes, entre los 2800-3200 m, habiéndose registrado en los departamentos de Amazonas, Ayacucho, Piura, Puno, San Martín y Pasco.

Material estudiado: Provincia de Oxapampa, Santa Bárbara, 3100-3300 m, M. I. La Torre 1541 (USM).

\section{Bromus pitensis Kunth}

Habita en el bosque montano oriental y se distribuye en los Andes de Ecuador, Perú y Bolivia. En el Perú se ha registrado en los departamentos de Ancash, Ayacucho, Cajamarca, Cusco, Huánuco, Huancavelica, Junín, Lima, Pasco, Puno.

Material estudiado: Provincia de Oxapampa, Cordillera Yanachaga, 3350-3620 m, D. N. Smith 7746 (MO).

\section{Género Festuca Linnaeus}

Planta perenne, cespitosa; inflorescencia en panoja terminal abierta o contraída; espiguillas multifloras, lateralmente comprimi- 
das, desarticulables por encima de la glumas y entre las flores; usualmente 5 nervadas, de ápice acuminado o cortamente aristado; pálea tan larga como la lema.

El género agrupa alrededor de 450 especies, de las cuales 36 especies se registran para el Perú y una especie para la zona de estudio. Se encuentran en regiones templadas extendiéndose en las montañas de los trópicos.

4. Festuca procera Humboldt, Bonpland \& Kunth

Su hábitat es el pajonal de Puna. Se le encuentra en Colombia, Ecuador, Perú y Bolivia. En el Perú se ha registrado en los departamentos de Ancash, Arequipa, Ayacucho, Huánuco, Huancavelica, Lima, La Libertad y Pasco.

Material estudiado: Provincia de Oxapampa, Santa Bárbara, 3100-3300 m, M.I. La Torre 1633 (USM).

\section{Género Poa Linnaeus}

Plantas perennes o anuales; algunas dioicas; inflorescencia en panojas contraídas o abiertas; espiguillas bifloras a multifloras, comprimidas lateralmente, desarticulándose por encima de las glumas y entre los antecios. Gluma inferior uninervada, la superior generalmente trinervada; lemas múticas, obtusas u agudas en el ápice, pentanervadas.

Propias de las regiones templadas y frías, extendiéndose hasta las montañas de los trópicos. Este género tiene 500 especies en el mundo, de las cuales 39 especies se registran en el Perú y una especie en la zona de estudio.

\section{Poa annua Linnaeus}

Su hábitat es en bordes de camino y chacras. Es una especie introducida desde Europa y que se ha naturalizado en América. Ampliamente distribuida en el Perú, desde casi el nivel del mar hasta cerca de $4500 \mathrm{~m}$. Con variaciones morfológicas de acuerdo con los niveles altitudinales donde habita. En el Perú se ha registrado en los departamentos de Arequipa, Ancash, Cusco, Huánuco, Huancavelica, Junín, La Libertad, Pasco y Puno.

Material estudiado: Provincia de Oxapampa, 2000 m, M. I. La Torre 1402 (USM).

\section{Género Poidium Nees}

El género cuenta con 19 especies todas distribuidas en Sudamérica, una especie para Perú, la misma que ha sido registrada en la zona de estudio.

\section{Poidium monandrum (Hackel) Matthei}

Habita en el pajonal de puna. Distribuida desde desde Colombia hasta la Argentina. En el Perú se le encuentra entre 2700-3850 m en los Andes. En el Perú esta especie ha sido registrada en los departamentos de Amazonas, Cajamarca, Cusco, Huánuco, Huancavelica, Junín y Pasco.

Material estudiado: Provincia de Oxapampa, Santa Bárbara 3100-3300 m, M. I. La Torre 1534 (USM)

\section{Tribu Phalaridae}

\section{Género Hierochloe R.Brown}

Planta perenne, rizomatosa; inflorescencia en panoja terminal; espiguillas 3 floras; glumas membranáceas subiguales, casi tan largas como la espiguilla. El género agrupa treinta especies, dos especies para Perú y una especie en la zona estudiada. Son generalmente de regiones templadas y del Ártico con excepción de África.

7. Hierochloe redolens (Vahl) Roemer \& Schultes

Habita en el pajonal de puna. Su distribución comprende Ecuador, Perú, Argentina, (Tierra del Fuego) y Australia. En el Perú se le encuentra en los Andes entre los 3300 y los 4400 $\mathrm{m}$. Se ha registrado en los departamentos de Amazonas, Ancash, Cajamarca y Cusco.

Material estudiado: Provincia de Oxapampa, Santa Bárbara 3300m, M. I. La Torre 1531 (USM). 


\section{Tribu Agrostideae}

\section{Clave para diferenciar los géneros de la tribu Agrostideae}

1a. Glumas persistentes en la panoja a la madurez.

2a. Raquila pilosa, prolongada al lado del antecio.

Calamagrostis

2b. Raquila glabra, comúnmente atrofiada. Agrostis

1b. Glumas caducas a la madurez.

\section{Polypogon}

\section{Género Agrostis Linnaeus}

Plantas anuales o perennes; espiguillas unifloras glumas iguales, agudas o acuminadas; lema membranácea, más corta que las glumas, mútica o aristada; pálea usualmente muy pequeña o ausente. Este género presenta 15 especies en el Perú y cinco especies en la zona estudiada.

\section{Clave para diferenciar las especies del genero Agrostis}

1a. Panoja contraída, densa, espiciforme o algo laxa, ramas floridas desde la base, adpresas o subadpresas.

2a. Panoja densa, espiciforme, comúnmente menor de $5 \mathrm{~cm}$ de largo, con ramas adpresas.

3a. Lema mútica

3b. Lema aristada

2b. Panoja subespiciforme, mayor de $5 \mathrm{~cm}$ de largo; ramas adpresas y algunas adpreso-ascendentes.

\section{A. tolucensis}

1b. Panoja abierta, laxa, hasta difusa; ramas desnudas en la base, ascendentes o divergentes, o si algo adpreso-ascendentes, entonces desnudas en la base.
4a. Lema aristada
A. boliviana
4b. Lema mútica
A. fasciculata

\section{Agrostis breviculmis Hitchc.}

Habita en el pajonal de puna. Su área de distribución comprende Perú, Bolivia y Chile. En el Perú se le encuentra en los departamentos de Amazonas, Ancash, Ayacucho, Cajamarca, Cusco, Huancavelica, Junín, La Libertad y Puno.

Material estudiado: Provincia de Oxapampa, Santa Bárbara, 3100-3300 m, M. I. La Torre 1544 (USM).

\section{Agrostis haenkeana Hitchc.}

Habita en el pajonal de puna. Se distribuye en Perú y Bolivia, en los niveles medios de los Andes. En el Perú se le encuentra entre los 3300 y los $4600 \mathrm{~m}$. Se ha registrado en los departamentos de Cusco, Junín y Puno.

Material estudiado: Provincia de Oxapampa, Santa Bárbara 3300 m, M. I. La Torre 1512 (USM).

\section{Agrostis tolucensis Kunth}

Habita en el pajonal de puna. Se distribuye desde México hasta Chile. En el Perú se le encuentra en la región altoandina, entre los 3000 y los $4500 \mathrm{~m}$, en los departamentos de Amazonas, Ancash, Cajamarca, Cusco, Huánuco, Huancavelica, Junín, Lima, La Libertad, Pasco y San Martín.

Material estudiado: Provincia de Oxapampa, Santa Bárbara, 3100- 3300 m, M. I. La Torre 1522 (USM).

\section{Agrostis boliviana Mez}

Habita en el pajonal de puna. Se le encuentra distribuido en Perú y Bolivia, en los niveles medios de los Andes. En el Perú se le encuentra en los flancos orientales andinos entre los $3300 \mathrm{y} \operatorname{los} 4000 \mathrm{~m}$.

Material estudiado: Provincia de Oxapampa, Santa Bárbara, 3300 m, M. I. La Torre 1538 (USM).

12. Agrostis fasciculata (Humboldt, Bonpland \& Kunth) Roemer \& Schultes

Su hábitat es el pajonal de Puna. Se distribuye en América tropical, Colombia, Ecuador, Perú y Bolivia. En el Perú se le ubica en los flancos orientales andinos, entre los $2900 \mathrm{y}$ los $3600 \mathrm{~m}$. Se ha registrado en los departamentos de Amazonas, Huánuco y San Martín.

Material estudiado: Provincia de Oxapampa, Santa Bárbara 3100-3300 m, M. I. La Torre 1699 (USM).

\section{Género Calamagrostis Adanson}

Plantas perennes; panojas abiertas o contraídas hasta espiciformes. Espiguillas unifloras; 
raquila desarticulable por encima de las glumas, prolongada detrás de la pálea en una cerda comúnmente pubescente; glumas iguales, agudas o acuminadas; lema de igual tamaño que las glumas o generalmente más corta; arista dorsal recta o geniculada. Antopodio (callo) híspido-pubescente, con pelos cortos o largos y abundantes; pálea algo más pequeña que la lema. Este género cuenta con alrededor de 270 especies, distribuidas en las regiones templadas, así como en las montañas de los trópicos. Para el Perú se ha registrado 41 especies y tres especies para la zona estudiada.

\section{Clave para diferenciar las especies del genero Calamagrostis}

1a. Callo (antopodio) con pelos abundantes, mayores de 1,5 mm de largo, usualmente mayores que la mitad del largo de la lema.

C. longearistata

1b. Callo (antopodio) con pelos menores de 1,5 mm de largo o a veces glabro.

2a. Panojas usualmente laxas, algo abiertas, las ramas ascendentes o extendidas.

C. tarmensis

2b. Panojas algo densas, las ramas adpresas o ascendentes.

C. macrophylla

13. Calamagrostis longearistata (Wedd.) Hackel ex Sodiro

Su hábitat son los claros y bordes de caminos en el bosque montano oriental. Se distribuye en Colombia, Ecuador, Perú y Bolivia. En el Perú se le encuentra en la parte baja de las vertientes orientales, entre $\operatorname{los} 1000 \mathrm{y}$ los $2600 \mathrm{~m}$, en los departamentos de Amazonas, Cajamarca, Cusco, Huánuco, Junín, La Libertad y Pasco.

Material estudiado: Provincia de Oxapampa, D. N. Smith 4093 (MO, USM); San Alberto, 2500 m, M. I. La Torre 1398 (USM).

\section{Calamagrostis tarmensis Pilg.}

$\mathrm{Su}$ hábitat es el bosque montano oriental. Se distribuye en Ecuador, Perú y Bolivia. En el Perú se ha reportado en los departamentos de Ancash, Cajamarca, Cusco, Huánuco, Huancavelica, Junín, La Libertad y Pasco.
Material estudiado: Provincia de Oxapampa, Santa Bárbara, D. N. Smith 8110 (MO).

15. Calamagrostis macrophylla (Pilg.) Pilg.

Habita en el pajonal de puna. Se distribuye en Colombia, Ecuador y Perú. En el Perú se ha registrado en los departamentos de Amazonas, Ayacucho, Huánuco, Huancavelica, Junín, La Libertad, Puno y Pasco

Material estudiado: Provincia de Oxapampa, Santa Bárbara 3100-3300 m, M. I. La Torre 1634 (USM).

\section{Género Polypogon Desf.}

Plantas perennes, cespitosas. Panícula terminal, espiguilla desarticulada junto con el pedicelo; glumas angostas, aristadas, uninervadas; lema más corta que las glumas, aristada, membranácea. Raquila no prolongada detrás de la flor. Las especies de este género se distribuyen en las regiones templado-cálidas del mundo y también en las montañas tropicales. Este género tiene 18 especies, cuatro especies en Perú y una especie para la zona estudiada.

16. Polypogon elongatus Humboldt, Bonpland \& Kunth

Se distribuye desde México hasta Argentina. En el Perú, ampliamente distribuida en la costa y niveles medios de los Andes, habiendo sido registrado en los departamentos de Amazonas, Arequipa, Cajamarca, Huánuco, Huancavelica, Junín, Lima, La Libertad, Puno, San Martín y Pasco.

Material estudiado: Provincia de Oxapampa, San Alberto, 2130-2350 m, M. I. La Torre 1334 (USM); Quebrada Tunqui, 1600-1800 m, M. I. La Torre 1479 (USM).

\section{Subfamilia Centothecoideae}

\section{Tribu Centotheceae}

\section{Género Orthoclada P. Beauv.}

Plantas perennes; láminas foliares elípticas, con pseudopeciolo notorio, inflorescencia en panoja abierta, espiguillas bifloras, aquilladas, desarticulables por debajo de las glumas, glumas subiguales; lemas 5-7 nervadas, acuminadas. El 
género cuenta con dos especies, una de América tropical y otra de África.

17. Orthoclada laxa (L. Richard) P. Beauv.

Su hábitat es el bosque tropical amazónico. Se distribuye desde el sur de México hasta Perú, Brasil y Bolivia. En el Perú se encuentra distribuida en la selva amazónica por debajo de los $700 \mathrm{~m}$, habiéndose registrado en los departamentos de Amazonas, Cusco, Junín, Loreto, Madre de Dios, Pasco, San Martín y Tumbes.

Material estudiado: Provincia de Oxapampa, Iscozacín-Villa América, 350-450 m, D. N. Smith 2829 (MO, USM).

\section{Género Zeugites P. Browne}

Plantas perennes. Láminas foliares lanceoladas hasta aovadas con nervios transversales además de las longitudes principales, con falso pecíolo; inflorescencia en panoja laxa; espiguillas multifloras, la flor más inferior femenina, las restantes masculinas; glumas con nervios transversales, truncadas o dentadas; flores masculinas agudas. Este género tiene 12 especies, una especie para Perú y la que se reporta para la zona de estudio.

\section{Steud.}

18. Zeugites mexicana (Kunth)Trin ex

Su hábitat es el bosque premontano, lugares sombreados, suelos húmedos. Su distribución es desde México hasta Bolivia. En el Perú se le localiza en el bosque premontano (ceja de la montaña), habiéndose registrado en los departamentos de Cusco y Pasco.

Material estudiado: Provincia de Oxapampa, Valle de Chontabamba a $15 \mathrm{~km}$ de Oxapampa 1830 m, D. N. Smith 4143 (MO, USM).

\section{Subfamilia Arundinoideae}

\section{Tribu Arundineae}

\section{Clave para diferenciar los géneros de la tribu Arundinoideae}

1a. Hojas aglomeradas sólo en la base de la caña, de 0.5-1 cm de ancho; planta cespitosa. Cortaderia 1b. Hojas distribuidas a lo largo de la caña, de $3-5 \mathrm{~cm}$ de ancho; planta rizomatosa.

Gynerium

\section{Género Cortaderia Stapf}

Plantas perennes, cespitosas, comúnmente dioicas, a menudo formando grandes matas, a menudo robustas; hojas grandes agrupadas en la base de la caña. Panoja por lo común grande, plumosa, raras veces pequeñas.

El género agrupa 24 especies, de las cuales 6 están registradas para el Perú y dos para la zona de estudio. Son mayormente de Sudamérica, pero cuatro especies han sido registradas en Nueva Zelanda y una en Nueva Guinea.

\section{Clave para diferenciar las especies del genero Cortaderia}

1a. Lema finamente denticulada y con arista bien desarrollada.

C. nitida

1b. Lema fuertemente bidentada, los dientes largos, setáceos.

C. bifida

\section{Cortaderia nitida (Kunth) Pilg.}

Habita en laderas expuestas. Se distribuye desde Venezuela hasta Perú. En el Perú se le encuentra en los valles interandinos y el flanco oriental altoandino del centro y norte, entre los 2500-3400 m, habiendo sido reportado en los departamentos de Amazonas, Ancash, Cusco y Pasco.

Material estudiado: Provincia de Oxapampa, Santa Bárbara 3100-3300 m, M. I. La Torre 1508, 1671 (USM).

\section{Cortaderia bifida Pilg.}

Habita en el borde del bosque montano y se distribuye en Centroamérica, Perú y Bolivia. En el Perú se encuentra con frecuencia en la Cordillera Oriental de los Andes y valles interandinos. Ha sido registrado en los departamentos de Amazonas, Ancash, Cajamarca, Cusco, Huánuco, Junín, La Libertad, Pasco y Puno.

Material estudiado: Provincia de Oxapampa, San Gotardo 2100-2650 m, D. N. Smith 4115 (MO), San Alberto, 2500 m, M. I. La Torre 1203, 1515 (USM). 


\section{Género Gynerium P. Beauv.}

Planta perenne, rizomatosa, con robustas cañas de hasta $10 \mathrm{~m}$ de altura; dioicas. Hojas situadas dísticamente en la parte superior de las cañas; panojas grandes. Género monotípico, distribuido en México, Indias Occidentales hasta Perú, Brasil y Bolivia.

\section{Gynerium sagittatum (Aubl.) P. Beauv.}

Su hábitat son los márgenes de rios y bordes de caminos. Se distribuye en las Indias Occidentales, sur de México hasta Paraguay, Argentina. En el Perú se le ubica a todo lo largo de los ríos de la amazonía y en la costa formando parte de los montes ribereños. Se ha registrado en los departamentos de Amazonas, Junín, Lima, Loreto y Madre de Dios.

Material estudiado: Provincia de Oxapampa, Iscozacín, 500 m, M. I. La Torre 1083 (USM).

\section{Subfamilia Chloridoideae}

\section{Tribu Eragrostideae}

\section{Género Eragrostis von Wolf}

Plantas anuales o perennes, estoloníferas, cespitosas; inflorescencia en panoja contraída o laxa; espiguillas multifloras; glumas 1 nervada, aquilladas; lemas obtusas, 3 nervadas; páleas de menor tamaño que la lema; raquila persistente. Este género presenta 350 especies en el mundo, 21 especies en el Perú y una especie en la zona estudiada.

22. Eragrostis tenuifolia (A. Rich.) Hochs. ex Steud.

Habita en bordes de camino, campos abiertos y cultivos abandonados. Originaria de Africa o India; introducida en América. En el Perú se la ubica en la costa y en la parte media y baja de los valles interandinos, entre los 600$2300 \mathrm{~m}$. Se le ha registrado en los departamentos de Cajamarca, Cusco, Huánuco, Junín, Piura y Pasco.

Material estudiado: Provincia de Oxapampa, San Alberto, 2130-2150 m, M. I. La Torre 1330 (USM), 1372 (USM).

\section{Tribu Sporoboleae}

\section{Clave para diferenciar los géneros de la tribu Sporoboleae}

1a. Lemas obtusas múticas; cariópside caedizo sin la lemay pálea en la madurez; pericarpio mucilaginosos cuando se humedece.

Sporobolus

1b. Lema aguda, comúnmente aristada; cariópside persistente en la lema y pálea en la madurez; pericarpio no mucilaginosos al humedecerlo. Muhlenbergia

Género Sporobolus R. Brown

Plantas anuales o perennes; inflorescencia en panoja abierta o contraída; espiguilla 1 flora, fusiforme, convexa en el dorso; lema mútica, 1 nervada; pálea casi del tamaño de la lema o ligeramente más larga; fruto cariópside no adherido a la pálea. Este género presenta 160 especies en el mundo, 10 especies en el Perú y dos especies en la zona estudiada.

\section{Clave para diferenciar las especies del genero Sporobolus}

1a. Panoja ligeramente laxa; gluma superior obtusa. S. jacquemontii

1b. Panoja espiciforme; gluma superior aguda.

\section{S. indicus}

\section{Sporobolus jacquemontii Kunth}

Su hábitat es el bosque tropical amazónico (selva baja). Su área de distribución abarca el sur de Estados Unidos de Norteamérica, Indias Occidentales, México, Ecuador, Perú y Bolivia. En el Perú se encuentra sólo en la cuenca amazónica, habiendo sido reportado en los departamentos de Loreto, Pasco y Ucayali.

Material estudiado: Provincia de Oxapampa, Iscozacín, 350 m, D. N. Smith 2816 (MO).

\section{Sporobulus indicus (Linnaeus) R. Brown}

Habita en campos abiertos, pastizales y bordes de camino. Especie introducida del Viejo Mundo, naturalizada en América. En el Perú se distribuye en la costa y en los Andes hasta los $3600 \mathrm{~m}$, habiéndose registrado en los departamentos de Cusco, Huanuco, Huancavelica, La Libertad, Lima y Pasco. 
Material estudiado: Provincia de Oxapampa, 2000 m, M. I. La Torre 1282 (USM).

\section{Género Muhlenbergia Schreber}

Planta anual o perenne, inflorescencia en panoja abierta o contraída o espiciforme; espiguillas lanceoladas, algo literalmente comprimidas, unifloras; glumas más cortas o tan largas como la lema; lema membranácea, convexa en el dorso, comúnmente con arista apical; pálea de igual longitud que la lema. Este género presenta alrededor de 160 especies en el mundo. El Perú cuenta con 10 especies de las cuales 2 están presentes en la zona estudiada.

\section{Clave para diferenciar las especies del genero Muhlenbergia}

1a. Plantas bajas, semirastreras, rastreras 0 decumbentes, menores de $10 \mathrm{~cm}$ de altura, lemas agudas.

M. ligularis

1b. Plantas erguidas o algo decumbentes, mayores de $15 \mathrm{~cm}$ de altura, lemas agudas o aristadas.

\section{M. flexuosa}

25. Muhlenbergia ligularis (Hackel) Hitchc.

Su hábitat es el pajonal de puna. Se distribuye en los andes centrales de Ecuador, Perú y Bolivia. En el Perú se ha registrado en los departamentos de Ancash, Cajamarca, Cusco, Huánuco, Huancavelica, Junín, Lambayeque, La Libertad, Pasco, Puno y San Martín.

Material estudiado: Provincia de Oxapampa, Santa Bárbara, 3300-3420 m, D. Smith, 8095; Santa Bárbara, 3100-3300 m, M. I. La Torre 1527 (USM).

\section{Muhlenbergia flexuosa Hitchc.}

Habita en el bosque premontano muy húmedo. Solo es conocida en la parte media de los Andes centrales del Perú y se ha registrado en los departamentos de Huánuco y Pasco.

Material estudiado: Provincia de Oxapampa, entre Oxapampa y Pozuzo, Ellenberg 8934 (USM); carretera entre quebrada Tunqui y Quebrada Honda, 1600-1800 m, M. I. La Torre 1490 (USM).

\section{Tribu Chlorideae}

\section{Clave para diferenciar los géneros de la tribu Chloridoideae}

1a. Espiguillas dispuestas en grupos de dos o tres, estos en racimos solitarios en el ápice de la caña.

Aegopogon

1b. Espiguillas solitarias o en pares y no en grupos, dispuestas en racimos solitarios, digitados o fasciculados o a lo largo del eje principal.

2a. Planta perenne, raquila prolongada en una cerda. Cynodon

1b. Planta anual, raquila no prolongada en una cerda. Eleusine

\section{Género Aegopogon Willd.}

Plantas anuales. Inflorescencia en racimos unilateralmente dispuestos en el eje central. Espiguillas en grupos de dos a tres, ligeramente pediceladas; espiguilla central sésil o pedicelada, uniflora, fértil. Existen sólo tres especies en el mundo, las cuales están registradas para el Perú. En la zona de estudio se registra una especie. Se distribuyen desde el Sur de los Estados Unidos de Norteamérica hasta Perú. Habita lugares abiertos y secos.

\section{Aegopogon cenchroides Kunth in Willd.}

Se le encuentra en campos abiertos, suelos pedregosos y en bordes de caminos. Ha sido registrada en México, Colombia, Venezuela, Perú y Bolivia. En el Perú se le encuentra ampliamente distribuida en los niveles medios de los Andes, entre los 2500-3500 m, habiendo sido registrada en los departamentos Amazonas, Ancash, Cajamarca, Cusco, Huánuco, Huancavelica, Junín, Lima, La Libertad y Pasco.

Material estudiado: Provincia de Oxapampa, vía río Yamaquizú, D. N. Smith, A. Pretel \& L. Acosta 1807 (USM); Prov. Oxapampa, San Alberto, M. I. La Torre 1364 (USM), 1339 (USM).

\section{Género Cynodon Richard}

Planta rizomatosa o estolonífera, perenne, con cañas rastreras que arraigan en los nudos; láminas foliares planas involutas, filiformes; inflorescencia en racimos digitados 
con espiguillas dispuestas a un solo lado del raquis; espiguillas angostamente aovadas, unifloras, comprimidas; glumas angostas, subiguales, más cortas que la lema, uninervada; lema aovada-oblonga, 3 nervada. Este género tiene ocho especies, dos especies se encuentran en Perú y una especie en la zona de estudio. Se distribuyen en los trópicos y partes cálidas de las zonas templadas.

\section{Cynodon dactylon (Linnaeus) Pers.}

Habita en campos abiertos. Está ampliamente distribuida en partes cálidas de ambos hemisferios. Es una especie introducida en América. En el Perú se le encuentra en la costa, selva tropical de la Amazonía y en los valles interandinos por debajo de los $3000 \mathrm{~m}$, habiéndose registrado en los departamentos de Arequipa, Ayacucho, Cajamarca, Lambayeque, Lima, La Libertad, Loreto y Tacna.

Material estudiado: Provincia de Oxapampa, San Alberto 2000 m, M. I. La Torre 1401 (USM).

\section{Género Eleusine Gaertn.}

Plantas anuales o perennes; cañas aplanadas; hojas lineares usualmente plegadas; vainas foliares aquilladas; inflorescencia en racimos digitados o subdigitados en el ápice de la caña; espiguillas multifloras, aovadas u oblongas, lateralmente comprimidas; raquila desarticulable entre las flores; glumas aquilladas más cortas que las lemas; lemas 3-5 nervadas, aquilladas, obtusas o agudas.

El género comprende nueve especies, mayormente del este de África.

\section{Eleusine indica (Linnaeus) Gaertn.}

Habita en campos abiertos. Es una especie introducida del Viejo Mundo, distribuida en toda la América Tropical. En el Perú se le encuentra en la costa, en la selva tropical amazónica y en los valles interandinos por debajo de los 2000 $\mathrm{m}$, a sido registrada en los departamentos de Amazonas, Cajamarca, Junín, Lima, Loreto, Madre de Dios, Pasco y San Martín.

Material estudiado: Provincia de Oxapampa, Iscozacín, 350 m, D. N. Smith 2821 (MO).

\section{Subfamilia Panicoideae}

\section{Tribu Paniceae}

\section{Clave para diferenciar los géneros de la tribu Paniceae (Adaptada de Tovar, 1993)}

1a.Espiguillas rodeadas por una o varias cerdas libres o soldadas en la base formando un involucro.

2a.Cerdas de la espiguilla persistentes en el raquis, de manera que las espiguillas caen solas en la madurez.

Setaria

2b. Cerdas de las espiguillas caducas, caen junto con las espiguillas en la madurez.

Pennisetum

1b. Espiguillas sin cerdas en la base.

3a.Inflorescencia en panoja abierta o contraída hasta espiciforme.

4a. Lema fértil blanda, algo membranácea; lema estéril bidentada en el ápice, generalmente aristada entre los dientes.

Melinis

4b. Lema fértil endurecida; lema estéril entera en el ápice.

5a. Lema fértil con dos pequeños apéndices membranáceos en la base o éstos reducidos a excavaciones o cicatrices.

Ichnanthus

5b. Lema fértil sin apéndices membranáceos, excavaciones o cicatrices en la base.

6a. Espiguillas con dos flores fértiles. Isachne

6b. Espiguillas con una sola flor fértil, la inferior estéril.

7a. Gluma inferior y gluma superior iguales, tan largas como la espiguilla.

Homolepis

7b. Gluma inferior más pequeña que la superior, raramente tan larga como la mitad o los $2 / 3$ de la superior.

8a. Lema y pálea fértil con una excavación en el ápice que es lanoso-pubescente; con las espiguillas dispuestas en forma oblicua en el pedicelo. Lasiacis

8b. Lema y pálea fértil sin excavación en el ápice que es glabro; con las espiguillas dispuestas verticalmente en el pedicelo.

Panicum

3b. Inflorescencia en espiga o racimo espiciforme unilateral, éstos digitados o esparcidos a lo largo del raquis, raramente solitarios.

9a. Lema fértil membranácea o ligeramente cartilaginosa con los márgenes no enrollados sobre la pálea.

Digitaria

9b. Lema fértil endurecida, fuertemente cartilaginosa, con los márgenes enrollados sobre la pálea. 
10a. Glumas o lema estéril largamente acuminada o aristada.

11a. Gluma inferior largamente acuminada, tuberculado-híspida.

Echinolaena

11b.Gluma inferior aristada, glabra o adpreso-pubescente, más no híspida.

Oplismenus

10b. Glumas o lema estéril múticas.

12a. Lema fértil con el dorso orientado hacia el raquis; espiguillas comúnmente aovadas u orbiculares, comúnmente plano-convexas.

Paspalum

12b. Lema fértil con el dorso orientado hacia afuera del raquis; espiguillas lanceoladas o elípticas, comúnmente biconvexas.

Axonopus

Género Setaria P. Beauv.

Plantas anuales o perennes; láminas planas o plegadas; inflorescencia en panoja abierta o contraída, hasta espiciforme; espiguillas múticas, sostenidas en la base por un pedicelo con una o más cerdas persistentes en el eje de la inflorescencia, cuando las espiguillas caen en la madurez. El género cuenta con 100 especies en el mundo, distribuidas en los trópicos y subtrópicos de ambos hemisferios. En el Perú encontramos 13 especies y una para la zona estudiada.

30. Setaria parviflora (Poir.) Kerguélen

Habita en campos abiertos y bordes de camino. Se distribuye desde Estados Unidos de Norteamérica hasta Argentina. En el Perú se le encuentra en los niveles medios de los Andes y se ha registrado de los departamentos de Amazonas, Arequipa, Cajamarca, Cusco, Huancavelica, Junín, Lambayeque, Lima, La Libertad y Puno.

Material estudiado: Provincia de Oxapampa, San Alberto, 2130 m, M. I. La Torre 1328 (USM), 1371 (USM).

\section{Género Pennisetum L. Richard}

Plantas anuales o perennes; inflorescencia en panoja terminal o axilar espiciforme, cilíndrica o subglobosa; cada espiguilla, o grupo de espiguillas, acompañada en la base de un involucro de cerdas que caen junto con las espiguillas. Este género presenta 70 especies y se distribuyen en todos los trópicos y subtrópicos. En el Perú hay 13 especies y tres en la zona de estudio.

\section{Clave para diferenciar las especies del genero Pennisetum}

1a. Inflorescencias apicales en caña primaria o en las ramas.

2a. Setas de la espiguilla de 0,9-1,2 cm de largo; panojas purpúreas.

P. purpureum

2b. Setas de la espiguilla, por lo menos una, de 2,5$3 \mathrm{~cm}$ de largo; panojas crema-pajizas.

P. peruvianum

1b. Inflorescencias apicales y axilares, estas últimas nacen comúnmente más de una en los nudos superiores de la caña.

P. bambusiforme

31. Pennisetum purpureum Schumach.

Habita en campos abiertos, cultivada como ornamental. Es nativa del África tropical y está extendida en forma cultivada como especie forrajera en los trópicos del mundo. En el Perú se ha registrado en los departamentos de Amazonas, Huancavelica, Junín, Lima, Loreto, Madre de Dios, Pasco y Ucayali.

Material estudiado: Provincia de Oxapampa, 1800 m, Irma Mauricio Colqui 05 (USM).

\section{Pennisetum peruvianum Trin.}

Habita en el bosque premontano oriental. Se distribuye en los niveles medios y bajos de los Andes orientales del Ecuador y Perú. Se ha registrado en los departamentos de Amazonas, Cajamarca, Huánuco, Pasco y San Martín.

Material estudiado: Provincia de Oxapampa, Huancabamba, 1660 m, D. N. Smith 6952 (MO, USM); San Alberto, 2200 m, M. I. La Torre 1468 (USM).

33. Pennisetum bambusiforme (E. Fourn.) Hemsl. ex B. D. Jacks.

Habita en el bosque montano oriental, en bordes de carreteras. Se distribuye desde el Sur de México hasta Perú. En el Perú se le encuentra en el flanco oriental andino, entre los 2000-2600 m, habiéndose registrado en los departamentos de Amazonas, Cajamarca, Cusco, Huánuco, Junín y Puno. 
Material estudiado: Provincia Oxapampa, Cerro Pajonal, 2550 m, D. N. Smith 2568 (MO); San Alberto, 2350 m, M. I. La Torre 1320 (USM), 1279 (USM).

\section{Género Melinis P. Beauv.}

Plantas anuales o perennes, a veces aromáticas. Cañas decumbentes en la base, vainas pilosas, lígula formada por una línea de pelos. Lámina foliar linear-lanceolada, plantas y pubescentes. Panoja laxa, a veces contraída, muy ramificada. El género cuenta once especies, distribuidos mayormente del África; es una especie pantropical. El Perú cuenta con una especie, la que se registra también en la zona estudiada.

\section{Melinis minutiflora P. Beauv.}

Habita en el bosque premontano oriental. Introducida del África, extendida en toda la América tropical. En el Perú se ha registrado en los departamentos de Amazonas, Cajamarca, Huánuco, Huancavelica, Junín, Loreto, Madre de Dios, Pasco y San Martín.

Material estudiado: Provincia de Oxapampa, 1800-2000 m, B. León 918 (USM); San Alberto, 2150 m, M. I. La Torre 1337 (USM).

\section{Género Ichnanthus P. Beauv.}

Plantas anuales o perennes; láminas foliares angostamente lanceoladas hasta aovadas, raramente lineares, planas; inflorescencia en panojas densas o abiertas, a veces con ramas espiciformes. Este género presenta 25 especies en todo el mundo, de los cuales once se registran en el Perú y 3 en la zona estudiada.

\section{Clave para diferenciar las especies del genero Ichnanthus}

1a. Lema fértil con dos apéndices alados en la base. I. panicoides

1b. Lema fértil sin apéndices en la base, sólo presenta dos cicatrices.

2a. Panoja terminal simple con 3-5 ramas algo distantes.

I. nemorosus

2b. Panoja terminal ramificada, las ramas algo juntas.

I. pallens

\section{Ichnanthus panicoides P. Beauv.}

Se le encuentra en el bosque tropical amazónico. Se distribuye desde Guyanas, Perú hasta Brasil. En el Perú se le encuentra en selva alta y baja de la amazonía, por debajo de los $1000 \mathrm{~m}$, habiendo sido registrado en los departamentos de Junín, Loreto, Madre de Dios, Pasco, Puno y San Martín.

Material estudiado: Provincia de Oxapampa, Iscozacín, 400 m, D. N. Smith \& J. Salick 8323 (MO); 325 m, D. N. Smith 3697 (MO); Iscozacín, $380 \mathrm{~m}$, R. Foster, M. Chanco \& J. Albán 7842 (USM).

36. Ichnanthus nemorosus (Sw.) Doell in Mart

Habita en el bosque premontano oriental. Se distribuye desde Jamaica hasta Perú y Brasil. En el Perú ocurre en el flanco oriental andino, en los departamentos de Amazonas, Cajamarca, Huánuco y Junín.

Material estudiado: Provincia de Oxapampa, 1850-1900 m, D. N. Smith 3150 (MO); entre Río Pescado y Laguna Grande, 560-580 m, M. I. La Torre, 1077 (USM).

37. Ichnanthus pallens (Sw.) Munro ex Bentham

Habita en el bosque tropical amazónico. Se distribuye desde América Central, Indias Occidentales hasta el norte de Argentina. En el Perú se le encuentra en la cuenca amazónica, por debajo de los $1200 \mathrm{~m}$, habiéndose registrado en los departamentos de Amazonas, Cusco, Huánuco, Junín, Loreto, Madre de Dios, Pasco, Puno y San Martín.

Material estudiado: Provincia de Oxapampa, Iscozacín, 400-500 m, R. Foster \& B. d'Achille 10044 (USM).

\section{Género Isachne R. Brown}

Plantas anuales o perennes; láminas foliares, lineares o lanceoladas hasta aovadas; inflorescencia en panoja contraída o abierta. Este género cuenta con 60-80 especies distribuidas en los trópicos y subtrópicos. El Perú 
cuenta con dos especies y de las cuales una ocurre en la zona de estudio.

\section{Isachne arundinacea (Sw.) Griseb.}

Habita en el bosque tropical amazónico. Se distribuye desde el Sur de México hasta Bolivia. En el Perú se encuentra en los flancos orientales de los Andes, habiéndose registrado en Huánuco y Pasco.

Material estudiado: Provincia de Oxapampa, Huancabamba-Pozuzo, 1000-1500 m, Robin Foster \& B.d'Achille, A. Brack, 10322 (USM); Quebrada Tunqui y Quebrada Honda, 1200 m, M. I. La Torre, 1489 USM).

\section{Género Homolepis Chase}

Plantas anuales o perennes con cañas decumbentes o erguidas; láminas foliares. Panícula cerrada o algo abierta. Hay tres especies en el mundo, dos en el Perú y una especie en la zona estudiada; se le encuentra desde México hasta Brasil.

39. Homolepis glutinosa (Sw.) Zuloaga $\&$ Soderstr.

Habita en el bosque tropical húmedo. Se distribuye desde México, Sudamérica hasta Argentina. En el Perú se le encuentra en la cuenca amazónica en los departamentos de Amazonas, Cajamarca, Huánuco, Junín, Pasco y San Martín.

Material estudiado: Provincia de Oxapampa, 1950 m, D. N. Smith \& A. Pretel 1493 (MO).

Género Lasiacis (Griseb.) Hitchc.

Plantas perennes, algunas veces anuales; cañas ramificadas, erguidas, subleñosas, decumbentes o algo trepadoras. Láminas foliares lineares hasta aovadas. Panículas extendidas o contraídas. Este género cuenta con 16 especies distribuidas en los trópicos del Nuevo Mundo. El Perú cuenta con seis especies, de las cuales dos ocurren en la zona de estudio.

\section{Clave para diferenciar las especies del género Lasiacis}

1a. Ramas de la panoja reflexas o ampliamente extendidas, vainas pulverulentas o glabras; lámina de 7-14 cm de largo por 1-2,2 cm de ancho.

\section{L. ligulata}

1b. Ramas de la panoja ascendentes o extendidas; vainas papiloso-híspidas o pubescentes; lámina de 9-19 cm de largo por 1,2-3,4 cm de ancho.

L. aculata

\section{Lasiacis ligulata Hitchc. \& Chase}

Se le encuentra en el bosque tropical amazónico. Se distribuye en la selva tropical y subtropical del neotrópico. En el Perú se le ubica en la cuenca amazónica, habiéndose registrado en los departamentos de Amazonas, Ayacucho, Cajamarca, Cusco, Huánuco, Junín, Loreto, Madre de Dios, Pasco, Puno, San Martín y Ucayali.

Material estudiado: Provincia de Oxapampa, cerca de Chorobamba, 1850 m, D. N. Smith 6961 (MO).

\section{Lasiacis maculata (Aubl.) Urban}

Habita en el bosque premontano. Difundida ampliamente desde México hasta Argentina. En el Perú se le encuentra en la cuenca amazónica de los departamentos de Amazonas, Ayacucho, Cajamarca, Huánuco, Junín, Loreto, Madre de Dios, Pasco, San Martín y Ucayali.

Material estudiado: Provincia de Oxapampa, Quebrada Tunqui y Quebrada Honda 1200 m, M.I. La Torre 1482 (USM).

\section{Género Panicum Linnaeus}

Plantas anuales o perennes, cespitosa, rizomatosas o estoloníferas. Cañas huecas, herbáceas o subleñosas que pueden ramificarse o no, erectas o decumbentes y radicantes en los nudos inferiores. Nudos pubescentes o glabros. Vainas abiertas, lígula membránacea, membranáceo-ciliado, muy raro ausente, láminas planas, lanceoladas, oval-lanceoladas, con la base a veces cordada, planas o convolutas. Inflorescencia en panícula laxa, a veces contraída hasta espiciforme. Eln el mundo se enciuentran aproximadamente 500 es- 
pecies distribuidas en los trópicos, subtrópicos y partes cálidas de la zona templada. En el Perú se encuentran 26 especies y tres en la zona estudiada.

\section{Clave para diferenciar las especies del genero Panicum}

1a. Racimos con raquis pubescente, pelos largos, blancos.

P. pilosum

1b. Racimos con raquis glabro.

2a. Cañas con nudos pubescentes; lema fértil fusiforme.

P. polygonatum

2b. Cañas con nudos glabros; lema fértil cilindrácea.

\section{P. laxum}

\section{Panicum pilosum Sw.}

Habita en el bosque tropical amazónico (selva baja). Se distribuye en partes bajas de América tropical y subtropical, desde el sur de México hasta Argentina. En el Perú está ampliamente distribuida como maleza en la cuenca amazónica, por debajo de los 1000 m, en los departamentos de Amazonas, Cusco, Junín, Loreto, Madre de Dios, Pasco y San Martín.

Material estudiado: Provincia de Oxapampa, Paujil, 500 m, M. I. La Torre 1065 (USM); Paujil, 500 m. P. Hocking s/n. (USM).

43. Panicum polygonatum Schrader in Schult.

Habita en el bosque tropical amazónico. Se distribuye desde México hasta Brasil y Paraguay. En el Perú está ampliamente difundida en la selva baja, en los departamentos de Amazonas, Huánuco, Junín, Loreto, Madre de Dios, Pasco, San Martín, Tumbes y Ucayali.

Material estudiado: Provincia de Oxapampa, Iscozacín, 350 m, Smith \& J. Salick 8335 (MO).

\section{Panicum laxum Sw.}

Habita en el bosque tropical amazónico. Se distribuye desde México hasta Paraguay. En el Perú está registrado para la parte media y baja de la cuenca amazónica, en los departamentos de Amazonas, Huánuco, Junín, Loreto, Madre de Dios, Pasco, San Martín, Tumbes y Ucayali.
Material estudiado: Provincia de Oxapampa, Paujil, 350 m, M. I. La Torre 1117 (USM), 1087 (USM), 1102 (USM).

\section{Género Digitaria Haller}

Plantas anuales o perennes; hojas lineares o angostamente lanceoladas planas; inflorescencia constituida por pocos a muchos racimos digitados o con el eje alargado, raramente los racimos son solitarios, raquis de los racimos plano triquetro. Agrupa 200 especies en el mundo distribuidas en las regiones tropical y subtropical. En el Perú se encuentran 10 especies, de las cuales, una esta en la zona de estudio.

\section{Digitaria horizontalis Willd.}

Habita en el bosque tropical amazónico, en campos abiertos. Se distribuye en América tropical y oeste de África. En el Perú se le encuentra en la cuenca amazónica, en el departamento de Loreto.

Material estudiado: Provincia de Oxapampa, Gran Pajonal, 1200 m., D. N. Smith 6687 (MO).

\section{Género Echinolaena Desv.}

Plantas anuales o perennes, hojas lanceoladas o lineares; inflorescencia en cortos racimos dispuestos en un eje terminal o axilar. Este género presenta 6 especies en el mundo, una especie en el Perú y una especie en la zona de estudio. Se le encuentra en bosques sabaneros de Madagascar y América.

46. Echinolaena minarum (Nees) Pilg.

Habita en el bosque tropical húmedo, en lugares ligeramente abiertos. Se distribuye en América Tropical, Perú, Bolivia y Argentina. En el Perú se encuentra en la parte media de los valles interandinos de los departamentos de Apurimac, Ayacucho, Cusco, Huancavelica, Junín y Pasco.

Material estudiado: Provincia de Oxapampa, Chorobamba, 1850 m, D. N. Smith 6966(USM).

Género Oplismenus P. Beauv.

Plantas perennes o anuales, rastreras. $\mathrm{Ca}$ ñas floríferas erectas o con nudos inferiores que enraízan, láminas foliares lineares o aovadas. Inflorescencia formada por racimos alargados 
dispuestos a lo largo del eje; raquis de los racimos con espiguillas en pares. Este género presenta cinco especies a nivel mundial, tres para el Perú y una para la zona de estudio. Beauv.

47. Oplismenus hirtellus (Linnaeus) P.

Se le encuentra en el bosque tropical amazónico o selva baja. Se distribuye en América tropical, desde México hasta Argentina. En el Perú se le encuentra en Ayacucho, Cajamarca, Cusco, Huánuco, Junín, Loreto, Madre de Dios, Pasco y San Martín.

Material estudiado: Provincia de Oxapampa, Iscozacín, 400-500 m, R. Foster \& B. d'Achille 10063 (USM).

\section{Género Paspalum Linnaeus}

Plantas anuales o perennes; inflorescencias compuestas por racimos solitarios o numerosos digitados o esparcidos a lo largo del eje florífero. Presenta aproximadamente 330 especies en el mundo distribuidas en los trópicos, pero mayormente de América. En el Perú se han registrado 47 especies y en la zona de estudio seis especies.

\section{Clave para diferenciar las especies del genero Paspalum}

1a. Raquis de los racimos conspicuamente membranáceo o foliáceo, alado; el ancho del raquis mayor que el largo de la espiguilla.

2a. Cañas comúnmente de más de $1 \mathrm{~m}$ de altura; espiguillas de 2,5-3 $\mathrm{mm}$ de largo.

P. candidum

2b. Cañas menores de 0,8 $\mathrm{m}$ de altura; espiguillas de 1,8- $2 \mathrm{~mm}$ de largo.

P. scabrum

1b. Raquis de los racimos no conspicuamente membranáceo, foliáceo o alado (en algunas especies ligeramente aladas), el ancho del raquis menor que el largo de la espiguilla.

3a. Inflorescencia constituida por dos racimos o espigas geminadas, raramente con tres racimos.

\section{P. conjugatum}

3b. Inflorescencia constituida por uno, tres o más racimos o espigas y si son dos no son geminados.

4a. Racimos solitarios en el ápice de la caña florífera; espiguillas con gluma inferior y superior.

\section{P. decumbens}

4b. Racimos tres o numerosos y si son dos no son geminados, dispuestos a lo largo de la caña florífera; espiguillas sin gluma inferior.

5a. Espiguillas de 1,2-1,4 $\mathrm{mm}$ de largo, aovadas o suborbiculadas.

P. paniculatum

5b. Espiguillas de 2,4-3 mm de largo, elípticas u oblongo-elípticas.

P. virgatum

48. Paspalum candidum (Humboldt \& Bonpland Kunth

Habita en el bosque premontano, bordes de camino. Se distribuye desde Venezuela, Colombia, Ecuador, Perú, Bolivia y Chile. En el Perú se le encuentra en los niveles medios de los valles interandinos, habiéndose registrado en los departamentos de Cajamarca, Huanuco, Huancavelica, Junín, La Libertad y Pasco.

Material estudiado: Provincia de Oxapampa vía Río Yamaquizú 1870 m, D. Smith, A. Pretel \& L. Acosta 1762 (MO).

\section{Paspalum scabrum Scribner}

Habita en el bosque montano oriental, en lugares abiertos o ligeramente sombreados. Se distribuye en Guatemala, Venezuela, Colombia, Ecuador y Perú. En el Perú se le encuentra en los niveles medios de los Andes, habiéndose registrado de los departamentos Amazonas, Huánuco, Lambayeque, Pasco, Piura.

Material estudiado: Provincia de Oxapampa, 1870 m, D. N. Smith \& A. Pretel, L. Acosta 1762 (MO).

\section{Paspalum conjugatum Bergius}

Ampliamente extendido en los bosques de la zona tropical y subtropical, tanto del Viejo Mundo como de América. En el Perú ha sido registrada en los departamentos de Amazonas, Ayacucho, Cajamarca, Cusco, Huanuco, Loreto, Madre de Dios, Puno, San Martín, Tumbes y Ucayali.

Material estudiado: Provincia de Oxapampa, Iscozacín, 350 m, D. N. Smith \& J. Salick 8340 (MO); Iscozacín, J. Salick 7345 (MO); Iscozacín, M. I. La Torre 1067, 1103 (USM). 


\section{Paspalum decumbens Sw.}

Habita en el bosque tropical amazónico. Se distribuye desde Centroamérica hasta Brasil y Bolivia. En el Perú se le encuentra en la cuenca amazónica, habiéndose reportado de los departamentos de Huanuco, Junín, Loreto, San Martín y Ucayali.

Material estudiado: Provincia de Oxapampa, Iscozacín, 350 m, D. N. Smith \& J. Salick 8339 (MO).

\section{Paspalum paniculatum Linnaeus}

Se le encuentra bosque tropical amazónico. Se distribuye desde México hasta Argentina. En el Perú está registrada para la selva baja y selva alta, por debajo de los $1600 \mathrm{~m}$; se le ha registrado en los departamentos de Amazonas, Ayacucho, Cajamarca, Cusco, Huánuco, Junín, Loreto, Madre de Dios y San Martín.

Material estudiado: Provincia de Oxapampa, Iscozacín, 350 m, D. N. Smith \& J. Salick 8343 (MO).

\section{Paspalum virgatum Linnaeus}

Se le encuentra en el bosque tropical amazónico. Ampliamente extendida en la América tropical, desde México hasta Argentina. En el Perú es muy común en la cuenca amazónica, por debajo de los 900 m, habiéndose reportado en los departamentos de Amazonas, Cusco, Huánuco, Junín, Loreto, Madre de Dios, Pasco y Puno.

Material estudiado: Provincia de Oxapampa, Iscozacín, D. N. Smith 2820 (MO).

\section{Género Axonopus P. Beauvois}

Plantas anuales o perennes, inflorescencia compuesta de dos o más racimos delgados, digitados o subdigitados. Cuenta con 110 especies en el mundo, ocho en el Perú y tres en la zona estudiada. Se distribuye en los trópicos y especialmente en Sudamérica.

\section{Clave para diferenciar las especies del genero Axonopus}

1a. Planta anual, delicada; cañas floríferas filiformes; espiguillas de 1,1-1,4 mm de largo.

A. capillaris 1b. Planta perenne; espiguillas de 2,6-3 mm de largo.

2a. Planta estolonífera; panoja con dos a tres racimos.

A.compressus

2b. Planta no estolonífera; panoja con más de tres racimos a numerosos racimos.

A. elegantulus

54. Axonopus capillaris (Lamark) Chase

Habita en el bosque premontano, en bordes de camino. Se distribuye desde Centroamérica hasta Bolivia. En el Perú se ha registrado en los departamentos de Huánuco y Junín.

Material estudiado: Provincia de Oxapampa, Gran Pajonal, 1200 m, D. Smith 6685 (MO).

55. Axonopus compressus (Sw.) P. Beauv.

Habita en el bosque tropical amazónico. Ampliamente distribuido en el trópico y subtrópico húmedo. En el Perú se le encuentra en la cuenca amazónica por debajo de los 1200 m, en los departamentos de Amazonas, Huánuco, Loreto y Ucayali.

Material estudiado: Provincia de Oxapampa, Iscozacín, 350 m, D. N. Smith \& J. Salick 8338 (MO).

56. Axonopus elegantulus (Pres1) Hitchc.

Habita en el bosque montano. Conocida solamente en los niveles medios de los Andes del Perú, habiéndose registrado en los departamentos de Apurimac, Cajamarca, Cusco, Huánuco, Huancavelica, Junín y San Martín.

Material estudiado: Provincia de Oxapampa, Palmazu, 2000 m, H. Van der Werff, G. Zuñiga, R. Arce \& W. Pariona 8406 (MO).

\section{Tribu Arundinelleae}

\section{Género Arundinella Raddii}

Plantas perennes o anuales; láminas foliares lineal, planas; inflorescencia en panoja que puede ser abierta o contraída. Este género presenta 47 especies en el mundo, dos especies en el Perú y una en la zona estudiada.

57. Arundinella berteroniana (Schult.) Hitchc. \& Chase

Habita en el bosque premontano oriental y 
bosque tropical amazónico. Se distribuye desde Indias Occidentales hasta Bolivia. En el Perú se localiza en la cuenca amazónica por debajo de los $750 \mathrm{~m}$, habiéndose reportado en los departamentos de Amazonas, Cusco, Huánuco, Junín, Loreto, Madre de Dios, Pasco, Puno y San Martín.

Material estudiado: Provincia de Oxapampa, Gran Pajonal, 1000 m, D. N. Smith 5316 (MO); Rió Iscozacín, 500 m, M. I. La Torre 1092 (USM).

\section{Tribu Andropogoneae}

\section{Clave para diferenciar los géneros de la tribu Andropogoneae}

1a. Inflorescencia en racimos apanojados, numerosos racimos situados a lo largo del eje común, más largo que el racimo inferior.

2a. Raquis de los racimos continuo; espiguillas desigualmente pediceladas; panoja blanquecina.

Imperata

2b. Raquis de los racimos articulados, fácilmente desarticulable en la madurez; espiguillas en pares; una sésil y otra pedicelada; panoja marrón. Eriochrysis

1b. Inflorescencia en racimos solitarios, apareados, subdigitados o fasciculados en el ápice de cada caña florífera o ramas.

3a. Racimos solitarios en cada espateola u hoja más superior, raramente apareados, pero entonces el raquis continuo.

Schizachyrium

3b. Racimos, dos o más en cada espateola u hoja más superior.

Andropogon

\section{Género Imperata Cyrillo}

Plantas perennes, rizomatosas; inflorescencia en panoja angosta, espiciforme. El género cuenta con ocho especies en el mundo, habitan las regiones tropicales y partes cálidas de la región templada. El Perú cuenta con cuatro especies y una en la zona estudiada.

\section{Imperata minutiflora Hackel}

Habita en el Monte Ribereño. Conocida solo en Perú y Bolivia. En el Perú se ha registrado en los departamentos de Lima, Lambayeque y Pasco.

Material estudiado: Provincia de Oxapampa, entre Río Pescado y Laguna Grande, 500 m, M. I. La Torre 1088 (USM).

\section{Género Eriochrysis P. Beauv.}

Planta perenne, cespitosa; inflorescencia en panícula cilíndrica, densa, marrón. Este género cuenta con 7 especies en el mundo, una en Perú, la misma que se registra en la zona estudiada.

\section{Eriochrysis cayennensis P. Beauv.}

Habita en lugares abiertos, bosque montano. Se distribuye en América Tropical y Subtropical, desde México hasta Argentina y Uruguay. En el Perú ha sido registrado de los departamentos de Pasco y San Martín.

Material estudiado: Provincia de Oxapampa, Gran Pajonal 2000 m, H. Van der Werff, G. Zuñiga, R. Arce \& W. Pariona 8407 (MO).

\section{Género Schizachyrium Nees}

Planta anual, perenne, inflorescencia en racimos simples solitarios y terminales o en seudopanoja con espateolas en la base de los racimos; entrenudos y pedicelos lineares o cupuliformes. El género cuenta con alrededor de 60 especies distribuidas en los trópicos y subtrópicos, generalmente en sabanas o bosques sabaneros. En el Perú se encuentran 6 especies de las cuales dos estan en la zona de estudio.

\section{Clave para diferenciar las especies del genero Schizachyrium}

1a. Inflorescencia paniculiforme con numerosos racimos; raquis de los racimos delgado y flexuoso; espiguillas ascendentes o subdivergentes.

S. microstachyum

1b. Inflorescencia con un solo racimo terminal o además con unos pocos racimos laterales inferiores; raquis de los racimos engrosado, recto y rígido; espiguillas adpresas o subadpresas.

S. sanguineum

60. Schizachyrium microstachyum (Desv. ex Ham.) Rosen., Arrill. \& Izag.

Habita en el bosque premontano, en bordes de camino. Se distribuye desde México hasta Argentina. En el Perú está ampliamente distribuida en la Cuenca Amazónica y parte baja de los valles interandinos por debajo de los $2200 \mathrm{~m}$, se ha registrado en los departa- 
mentos de Amazonas, Cajamarca, Cusco, Huánuco, Junín, Puno y San Martín.

Material estudiado: Provincia de Oxapampa, alrededores de San Alberto, 1900 m, M. I. La Torre 1399 (USM).

61. Schizachyrium sanguineum (Retz.) Alston

Habita en el bosque montano oriental. En suelos rocosos o en campos abiertos. Se distribuye en América desde Estados Unidos de Norteamérica hasta Argentina. En Perú está ampliamente distribuida en los niveles medios de los Andes, entre los 2000- 3300 m. Se ha registrado en los departamentos Amazonas, Ancash, Cajamarca, Cusco, Huánuco, Huancavelica, Junín, Lima, La Libertad y Puno.

Material estudiado: Provincia de Oxapampa, Huancabamba, D. Smith \& J. Canne 5769 (MO).

\section{Género Andropogon Linnaeus}

Plantas anuales o perennes; inflorescencia terminal o axilar, en racimos espiciformes geminados, digitados o subdigitados, excepcionalmente acompañados por una bráctea espatiforme, formando una seudopanoja, entrenudos y pedicelos comúnmente ciliados o pilosos.

\section{Clave para diferenciar las especies del genero Andropogon}

1a. Inflorescencia con numerosos racimos, apanojados, corimbosos; planta robusta, comúnmente de 1-1,5 m de altura

A. bicornis

1b. Inflorescencia con pocos racimos, largamente pedunculados a veces subpanojados, laxos; plantas no robustas, menores de $0,9 \mathrm{~m}$ de altura.

\section{A. leucostachyus}

\section{Andropogon bicornis Linnaeus}

Habita en bordes de camino, campos abiertos secos. Se distribuye al sur de México, Centroamérica y América del Sur. En el Perú se le encuentra en la cuenca Amazónica. Ha sido reportado en los departamentos de Amazonas, Cajamarca, Cusco, Huánuco, Junín, Loreto, Madre de Dios, Pasco y Ucayali.
Material estudiado: Provincia de Oxapampa, Pozuzo 830-900 m A. Gentry, D. Smith \& R. Vásquez 40095 (MO).

63. Andropogon leucostachyus Humboldt, Bonpland \& Kunth

Habita en el bosque premontano oriental en campos abiertos y bordes de camino. Se distribuye al Sur de México, Uruguay hasta Argentina. En el Perú ha sido registrado en los departamentos de Amazonas, Cusco y Pasco.

Material estudiado: Provincia de Oxapampa, Gran Pajonal, 1250 m, D. N. Smith 5060 (USM, MO).

\section{Discusión y Conclusiones}

En este trabajo (primera y segunda parte) hemos preferido usar el sistema de clasificación empleado por Tovar (1993), principalmente para mantener coherencia con los trabajos previos (La Torre, 1998). Con esta segunda parte completamos el conocimiento de la diversidad de las Poáceas del Parque Nacional Yanachaga-Chemillén.

Las 63 especies (Tabla 1) están distribuidas en cinco subfamilias, de las cuales la más diversa es la Panicoideae con 3 tribus, 18 géneros y 34 especies. Esto último confirma el patrón de distribución de esta subfamilia (Tovar, 1998). Esta subfamilia es la más diversa en la región amazónica, que a su vez es la mayor área en la zona estudiada. Las Pooideae ocupan el segundo lugar en diversidad con cuatro tribus, nueve géneros y 16 especies, esta menor diversidad es explicable, debido a que este grupo es predominante en ecosistemas más fríos como la puna o el páramo (Tovar, 1998); siendo estos de areas reducidas en la zonas de estudio.

Las otras tres subfamilias cuentan con menos de 10 especies cada una de ellas. Para las Centothecoideae registramos las mismas dos especies que se citan para el Perú (Tovar, 1993). En el Parque las Arundinoideae están representadas por dos especies de Cortaderia y por Gynerium sagittatum, esta ultima en poblaciones muy reducidas, a diferencia de otras locali- 
Tabla 1. Lista de las especies y ubicación taxonómica de las Subfamilias de las Poáceas registradas para el Parque Nacional Yanachaga-Chemillén, excluyendo a las Bambusoideae

SUBFAMILIA POOIDEAE (FESTUCOIDEAE)

Tribu Stipeae

1. Ortachne erectifolia (Swallen) Clayton

Tribu Poeae (Festuceae)

2. Bromus segetum Kunth

3. Bromus pitensis Kunth

4. Festuca procera Humboldt, Bonpland \& Kunth

5. Poa annua Linnaeus

6. Poidium monandrum (Hackel) Matthei

Tribu Phalaridae

7. Hierochloe redolens (Vahl) Roemer \& Schultes

Tribu Agrostideae

8. Agrostis breviculmis Hitchc.

9. Agrostis haenkeana Hitchc.

10. Agrostis tolucensis Kunth

11. Agrostis boliviana $\mathrm{Mez}$

12. Agrostis fasciculata (Humboldt, Bonpland \&

Kunth) Roemer \& Schultes

13. Calamagrostis longearistata (Wedd.) Hackel ex Sodiro

14. Calamagrostis tarmensis Pilg.

15. Calamagrostis macrophylla (Pilg.) Pilg.

16. Polypogon elongatus Humboldt, Bonpland \& Kunth

\section{SUBFAMILIA CENTOTHECOIDEAE}

Tribu Centotheceae

17. Orthoclada laxa (L. Richard) P. Beauv.

18. Zeugites mexicana (Kunth)Trin ex Steud.

SUBFAMILIA ARUNDINOIDEAE

Tribu Arundineae

19. Cortaderia nitida (Kunth) Pilg.

20. Cortaderia bifida Pilg.

21. Gynerium sagittatum (Aubl.) P. Beauv.

SUBFAMILIA CHLORIDOIDEAE

Tribu Eragrostideae

22. Eragrostis tenuifolia (A. Rich.) Hochs. ex Steud.

Tribu Sporoboleae

23. Sporobolus jacquemontii Kunth

24. Sporobulus indicus (Linnaeus) R. Brown

25. Muhlenbergia ligularis (Hackel) Hitchc.

26. Muhlenbergia flexuosa Hitchc.

Tribu Chlorideae

27. Aegopogon cenchroides Kunth in Willd.

28. Cynodon dactylon (Linnaeus) Pers.

dades de selva baja, en las cuales inclusive forman asociaciones conocidas como «cañabravales» (Encarnación, 1993; Kalliola etal., 1987).

La diversidad de la flora agrostológica del Parque Nacional Yanachaga-Chemillén es comparable con las de otras áreas naturales protegidas de la vertiente oriental de los Andes. Para el Parque Nacional Río Abiseo se han registrado 75 especies de Poáceas en las mismas seis subfamilias (Young \& León, 1990; La Torre, et al. 2001), y que comparte con el P. N. Yanachaga-Chemillén 14 especies. Pero existen diferencias marcadas en términos de composición específica de las subfamilias, tal
29. Eleusine indica (Linnaeus) Gaertn.

\section{SUBFAMILIA PANICOIDEAE}

\section{Tribu Paniceae}

30. Setaria parviflora (Poir.) Kerguélen

31. Pennisetum purpureum Schumach.

32. Pennisetum peruvianum Trin.

33. Pennisetum bambusiforme (E. Fourn.) Hemsl. ex B. D.Jacks.

34. Melinis minutiflora P. Beauv.

35. Ichnanthus panicoides P. Beauv.

36. Ichnanthus nemorosus (Sw.) Doell in Mart.

37. Ichnanthus pallens (Sw.) Munro ex Bentham

38. Isachne arundinacea (Sw.) Griseb.

39. Homolepis glutinosa (Sw.) Zuloaga \& Soderstr.

40. Lasiacis ligulata Hitchc. \& Chase

41. Lasiacis maculata (Aubl.) Urban

42. Panicum pilosum Sw.

43. Panicum polygonatum Schrader in Schult.

44. Panicum laxum Sw.

45. Digitaria horizontalis Willd.

46. Echinolaena minarum (Nees) Pilg.

47. Oplismenus hirtellus (Linnaeus) P. Beauv.

48. Paspalum candidum (Humboldt \& Bonpland

Kunth

49. Paspalum scabrum Scribner

50. Paspalum conjugatum Bergius

51. Paspalum decumbens Sw.

52. Paspalum paniculatum Linnaeus

53. Paspalum virgatum Linnaeus

54. Axonopus capillaris (Lamark) Chase

55. Axonopus compressus (Sw.) P. Beauv.

56. Axonopus elegantulus (Presl) Hitchc.

Tribu Arundinelleae

57. Arundinella berteroniana (Schult.) Hitchc. \& Chase

\section{Tribu Andropogoneae}

58. Imperata minutiflora Hackel in DC

59. Eriochrysis cayennensis P. Beauv.

60. Schizachyrium microstachyum (Desv. ex

Ham.) Rosen., Arrill. \& Izag.

61. Schizachyrium sanguineum (Retz.) Alston

62. Andropogon bicornis Linnaeus

63. Andropogon leucostachyus Humboldt, Bonpland \& Kunth

es así que en el P. N. Yanachaga-Chemillén la subfamilia con mayor número de especies es Panicoideae (34 especies), mientras que en el P. N. Río Abiseo son las Pooideae con 38 especies. Esta mayor diversidad de Pooideae se debe que el rango altitudinal estudiado en el $\mathrm{P}$. N. Río Abiseo es mayor, llegando hasta los $4200 \mathrm{~m}$. Otra diferencia importante es que en el P. N. Río Abiseo hay una menor diversidad de Bambusoideas ( 9 especies versus 23 ), esto puede deberse a una menor intensidad de colecta en la zona baja de este Parque. Por otro lado si bien no hay aún un estudio especifico de las Poáceas en el Parque Nacional de Manu, 
basándonos en la información publicada, estimamos que esta área natural protegida, cuenta con alrededor de 90 especies en 41 géneros, 17 tribus y seis subfamilias (Foster, 1987, 1990; Cano, 1994; Young \& Cano, 1994; Cano et al., 1995). El P. N. Yanachaga-Chemillén comparte con el P. N. Manu 18 especies de Poáceas; pero este ultimo es más diverso en Pooideas, además son conspicuas las asociaciones Guadua spp. (Bambusoideae), conocidas localmente como «pacales».

En el presente se reporta 59 especies de Poáceas que no habían sido citadas en publicaciones previas y que se consideran como nuevos registros para la flora del Parque.

Si bien consideramos que es necesario continuar con la exploraciones botánicas en el Parque Nacional Yanachaga-Chemillén para completar el conocimiento de su flora, el presente trabajo hace una importante contribución al incrementar a 86 especies de Poáceas conocidas para este Parque. Esta diversidad de Poáceas es representativa de las vertientes orientales de los Andes peruanos.

\section{Agradecimientos}

Los autores agradecen el apoyo financiero del Fondo de Desarrollo Universitario (FEDU) de la Universidad Nacional Mayor de San Marcos, del Consejo Nacional de Ciencia y Tecnología (CONCYTEC), The University of Maryland Baltimore County, The Nature Conservancy y la Fundación Peruana para la Conservación de la Naturaleza. Expresamos nuestro reconocimiento a Kenneth R. Young, Blanca León, José Roque y Mónica Arakaki por el apoyo en el trabajo de campo, y/o la revisión del manuscrito. Al Biólogo Pedro Aguilar Delgado por su valioso apoyo logístico, así como al personal del P. N. Yanachaga-Chemillén.

\section{Literatura citada}

Cano, A. 1994. Sinopsis de la flora fanerogámica altoandina del Parque Nacional del Manu, Cusco. Universidad Nacional Mayor de San Marcos, Tesis para Optar el Grado de Magister en Botánica, Lima.
Cano, A., K. R. Young, B. Leon \& R. B. Foster. 1995. Composition and Diversity of Flowering Plants in the Upper Montane Forests of Manu National park, Souhtern Peru. In Churchill, S. P., H. Baslev, E. Forero \& J. Luyteyn (eds.), New York Botanical Garden, Bronx.

Encarnación, F. 1993. El bosque y las formaciones vegetales en la llanura amazónica del Perú. Alma Mater 6: 95-114.

Foster, R. B. 1987. Plantas del Parque Manu: 1987 Checklist Informe al Ministerio de Agricultura, Lima.

Foster, R. B. 1990. The Floristic Composition of the Rio Manu Floodplain Forest. In A.H. Gentry (Ed.) Four Neotropical Rain Forets : 565-572

Kalliola, R.,J. Salo \& Y. Mäkinen. 1987 Regeneración Natural de Selvas en la Amazonía Peruana 1: Dinamica Fluvial y Sucesión Ribereña. Memorias de Historia Natural. No 18.

La Torre, M. I., A. Cano y O. Tovar. 2003. Las Poáceas del Parque Nacional Yanachaga-Chemillén, Oxapampa, Pasco, Perú. Parte I: Bambusoideae. Revista peruana de biología 10(2): $145-154$.

La Torre, M., A. Cano, K. Young, B. Leon y J. Roque. 2001. Flora agrostológica del Parque Nacional Río Abiseo (San Martín, Perú). Libro de Resúmenes de la $\mathrm{X}$ Reunión Científica del ICBAR, 25-27 abril, Lima. Pp. 44.

La Torre, M. I. 1998. Estudio taxonómico de la familia Poaceae del Parque Nacional YanachagaChemillén (Oxapampa, Pasco, Perú). Universidad Nacional Mayor de San Marcos, Tesis para Optar el Grado de Magíster en Botánica, Lima.

Tovar, O. 1998. Diversidad de las gramíneas (Poaceae) del Perú. En Halffter, G. (Compilador). Acta Zoológica Mexicana Nueva Serie, Volumen especial. Pp. 117-131.

Tovar, O. 1993. Las Gramíneas (Poaceae) del Perú. Ruizia, Tomo 13, Madrid. 481 pp

Tovar, O. 1972. Revisión de las especies peruanas del género Festuca. Memorias Museo Historia Natural 16: 1-94.

Tovar, O. 1965. Revisión de las especies peruanas del género Poa. Memorias del Museo de Historia Natural 15:1-66.

Tovar, O. 1960. Revisión de las especies peruanas del género Calamagrostis. Memorias del Museo de Historia Natural 11:1-91

Young, K. R. \& B. Leon. 1990. Catálogo de las plantas de la zona Alta del Parque Nacional Rio Abiseo, Perú. Publicaciones del Museo de Historia Natural. Serie B, Botánica 34: 1-37.

Young, K. R. \& A. Cano. 1994. Aporte Florístico de la puna del Parque Nacional del Manu, Perú. Boletín de Lima 16(91-96): 381-391. 